\title{
Strategic Planning Under the Local Government Act 2002: Towards Collaboration or Compliance?
}

\author{
Mike Reid, Claudia Scott and Jeff McNeill
}

\section{Introduction}

By July 2006 all 85 local authorities expect to have their 10-year Long Term Council Community Plans (LTCCPs) signed and sealed, and passing muster with an unqualified audit report. The new Local Government Act 2002 (LGA 2002) has provided councils with general empowerment and introduced a new purpose (section 3) for local government: to 'promote the social, economic, cultural and environmental well-being of communities now and for the future'.

Local Futures is a five-year Foundation for Research, Science and Technology-funded research project on strategic policy and planning, based at the School of Government. Its focus is on strategic policy and planning in local government and the impact of the LGA 2002 on strategic planning capability and performance.

This article reports on some changes to strategic planning practices observed in the 19 councils participating in the Local Futures project as they prepared transitional LTCCPs under the new legislation. The implementation of the LGA 2002 is further detailed in Local Government, Strategy and Communities, a monograph which will be published by the Institute of Policy Studies in late May.

Of particular interest are changes to strategic planning practices and the degree to which the LGA 2002 will meet its intended objectives: enhanced community participation, better strategic planning practices and a whole-of-government approach to strategy and policy. The legislation will be reviewed in 2007 to determine whether it is 'fit for purpose' or in need of improvement.

\section{LGA 2002}

Under the LGA 2002, each local authority in New Zealand must prepare a Long Term Council Community Plan which articulates the economic, social, environmental and cultural outcomes desired by its community. In addition to outlining the council's 10year financial strategy and how it will be funded, the LTCCP links high-level 'community outcomes' to the council's outputs and activities.

As Tim Shadbolt, Mayor of Invercargill, said simply: 'Parliament has the right to force us to have a Long Term Council Community Plan - whether we want to do one or not' (Southland Times, 25 March 2006). The new legislation places new pressures on authorities, requiring them to adopt the roles of facilitator, negotiator and catalyst in strategy development. However, achieving outcomes for communities often requires alignment of the strategies and activities of other councils, central government agencies, and organisations in the private and community sectors.

\section{Strategic planning in organisations and communities}

Bryson, a well-known writer on strategic planning in public and not-for-profit organisations, defines strategic planning as 'a disciplined effort to produce fundamental decisions and actions that shape and guide what an organization (or other entity) is, what it does and why it does it' (Bryson, 2004, p.6). Strategic planning in local government settings has been historically associated with land-use planning, the preparation of district plans, and the use of zoning and other regulatory instruments to govern resource users' activities.

Following the consolidation of local government numbers in 1989 the majority of councils voluntarily adopted strategic plans, which were primarily organisational strategies. Two in particular, Manukau and Porirua, took an innovative approach, with strategic planning characterised by the extensive involvement of the community and other agencies. Both councils were engaged in what Bryson would describe as 'collaborative 
strategic planning', which more recently McKinlay (2005) has called 'community strategic planning'. Officials working on the development of the LGA 2002 were familiar with the Porirua and Manukau models, and they are reflected in the requirements of section 81 of the Act, which prescribes the community outcomes process.

Collaboration among organisations is a key element of successful strategic planning in an environment with highly fragmented units of government and service delivery. Chris Huxham, a prominent writer in the field, speaks of the need for 'collaborative thuggery' to beat off those whose behaviours put the collaborative advantage at risk (Huxham, 2003).

Strategic planning for communities is different from strategic planning in organisations. It requires councils to facilitate community conversations in order to identify, aggregate and prioritise the community's preferences. Community strategy works within an environment of pervasive ambiguity, where multiple agencies contribute to goals and where accountability is diffuse.

\section{Strategic planning and strategic thinking}

Mintzberg (1998) suggests that strategic planning is about analysis - breaking down a goal into steps and formalising them so that they can be implemented, and articulating the expected consequences of each step. He defines strategic thinking as an activity which is concerned with synthesis rather than analysis. It requires intuition and creativity to formulate a coherent vision of where an organisation should be heading.

Liedtka observes that strategic thinking is generally intuitive, experimental and disruptive and reaches beyond what purely logical thinking can achieve (in Lawrence, 1999). The tensions between strategic planning (which creates alignment) and strategic thinking (which disrupts alignment) must be managed to develop strategies which assist communities to both adapt to and shape the future.

\section{Community outcomes}

The LGA 2002 requirement that councils facilitate a community outcomes process was designed to meet a number of objectives, some of which are not complementary. There is a steering function concerned with setting strategic direction, and an accountability function concerned with ensuring that general empowerment is used to fulfil community expectations and with giving local government a key role in fostering collaborative governance.

Councils have used various processes to identify community outcomes. A number of areas, such as Taranaki and Southland, adopted regional approaches which conferred advantages in dealing with issues that crossed territorial jurisdictions, in enabling the involvement of external stakeholders, and also in improving internal capacity. There was also variation regarding the role of officials and elected members, and the extent to which councils approached their communities with a 'blank sheet' or a draft set of outcomes.

Many of the policy levers required to achieve identified outcomes are held by agencies external to the councils, especially central government. Many outcomes address issues of health, education or social equity, but New Zealand local authorities have a relatively narrow task profile in these areas and represent a very small share of public expenditure (less than 10\%). Whether or not LTCCPs will have a measurable effect on the achievement of community outcomes may in the end depend on the quality of the relationships established with central government agencies and other stakeholders.

Most outcomes of the 19 councils researched are explicitly or implicitly related to the four categories of well-being specified by the Act. Two-thirds of the councils surveyed have specified outcomes relating to the health of their communities; a third seek educated communities; safety and access to essential services are other commonly desired outcomes. Economic outcomes are often phrased in generous terms, such as 'thriving', 'strong', 'secure', 'robust', 'buoyant', 'prosperous' and 'wealthy'. Environmental outcomes included clean water and air, and sustainable use of resources. The elusive concept of cultural well-being inspires more limited ambitions: 'vibrant' is an adjective chosen by four councils. 'Culture' for some councils seems to mean either district identity or discretionary activities such as recreation, rather than embracing every aspect of 'the way we do things around here'.

Most councils set about half a dozen outcomes, though some had significantly more. The variation reflects the different levels at which outcomes are pitched. Carterton, 
for example, identified just four generic high-level community outcomes, though it also recognised its more geographically specific transport and communications issues:

- Access to transport and communications systems that best meet the diverse needs of the district.

- Clean land, water and air for present and future generations.

- Buoyant local economy.

- A safe, healthy and educated community.

Central Hawke's Bay set nine prioritised community outcomes:

- A lifetime of good health and well-being.

- An environment that is appreciated, protected and sustained for future generations.

- Safe and secure communities.

- Transport infrastructure and services that are safe, effective and integated.

- A strong, prosperous and thriving economy.

- Strong regional leadership and a sense of belonging.

- Supportive, caring, inclusive communities.

- Communities that value and promote their unique culture and heritage.

- Safe and accessible recreational facilities.

These generalised aspirations sometimes mask specific local issues. For example, the upbeat 'A lifetime of good health and well-being', conceals several pressing public health issues: poor reticulated water and waste water systems, a shortage of general practitioners, and perceived poor access to primary and emergency health services.

Some councils have grasped the fact that LTCCPs do not commit them to delivering all of the specified community outcomes, and have sought the help of other, more appropriately equipped agencies. The councils themselves can take on various roles, such as lead agency, partner or facilitator, with various degrees of active involvement. Western Bay of Plenty clearly differentiates its roles in the pursuit of various community outcomes: for example, it says it is the lead agency in ensuring 'efficient and safe' infrastructure and services; a partner in securing 'a variety of living and working opportunities'; a facilitator of coordination between 'organisations which provide services'; and an advocate in respect of some more elusive goals - 'good education facilities', 'a positive community spirit' and a 'healthy and safe lifestyle'.

Several councils provide or subsidise assets such as medical centres for private sector use in order to achieve specific outcomes. For example, the Hurunui District Council owns three of the district's five medical centres and the medical practitioners' residences in several towns. The Grey District Council plans to build a medical centre to make the district more attractive to workers; its rationale concerns economic development rather than health outcomes per se.

All the councils have tried to determine what strategic issues face their communities as a basis for justifying activities designed to secure particular outcomes, but in some cases there is an apparent desire to put a positive light on the community and to not 'frighten the horses'. Many chose to categorise their issues explicitly or implicitly within the economic, social, environmental and cultural areas of well-being specified by the Act.

\section{Strategic planning practices}

Practices showed considerable diversity across our sample of 19 authorities. Some promoted a culture of innovation and engagement, while others reflected a minimalist approach centred on compliance. Their approaches to the relationship between their community outcomes and the four elements of well-being provide a good example. Some councils put considerable effort into linking the community's outcomes to the four areas of well-being specified in the Act, often spreading outcomes evenly across them. Other councils made little or no specific link with them.

Underlying the LGA 2002 is the assumption that local authority boundaries provide a good way of articulating community interests in particular outcome areas. This may not necessarily be the case. Similarly, if the outcomes are to be important in shaping priorities one must expect that outcomes will be tailored to reflect differences across jurisdictions.

In fact, most councils have maintained a high-level focus in specifying outcomes. Doing so may have eased the burden of linking council outputs and activities to outcomes, but it has produced remarkably similar 
strategic plans. Such plans offer limited local guidance regarding the distinctive character, preferences and priorities of individual communities. Also of concern is the limited attention plans are giving to possible tradeoffs required to meet the competing demands of different stakeholder groups.

At the same time, some councils have reflected a strong compliance orientation. The community outcomes in many of the transitional LTCCPs were written by council staff and councillors, though often inspired by earlier strategic planning efforts and community consultations.

\section{Facing growth}

Many councils specified particular issues, such as transport and growth or decline, separately from the well-being framework. These were frequently the issues perceived as overwhelmingly important, with extensive ramifications, and often especially intractable - in some cases having implications for the viability of the communities in question. Such issues typically emerged acutely in districts facing population growth or decline. We look here at two growth councils to illustrate the range of responses councils took to these daunting issues within the framework afforded by the legislation.

\section{Facing growth: Waipa and Western Bay of Plenty District Councils}

Waipa and Western Bay of Plenty District Councils serve superficially similar growth districts, so they face a similar dominant issue, but they have taken quite different strategic decisions in response.

Waipa district in the central Waikato is agriculturallybased. Two milk processing plants provide employment, along with agricultural service industries. Hamilton, which is outside the district, also provides significant employment.

Western Bay of Plenty district is a third larger than Waipa, and forms the hinterland surrounding the port city of Tauranga. It too is rural, almost half the district being forested, and less than $1 \%$ urban. Agriculture and horticulture (often on lifestyle blocks), along with forestry, form the economic base of the district. Tauranga is the major manufacturing and service centre for the region and a major provider of employment.

The two councils share many characteristics: both serve prosperous, medium-sized rural-based districts, each with about 40,000 inhabitants, and each adjacent to a much larger city that is growing - Hamilton and

Figure 1: Projected population growth 2001-21 for the 17 participating city and district authorities (medium growth scenario). Statistics New Zealand data.

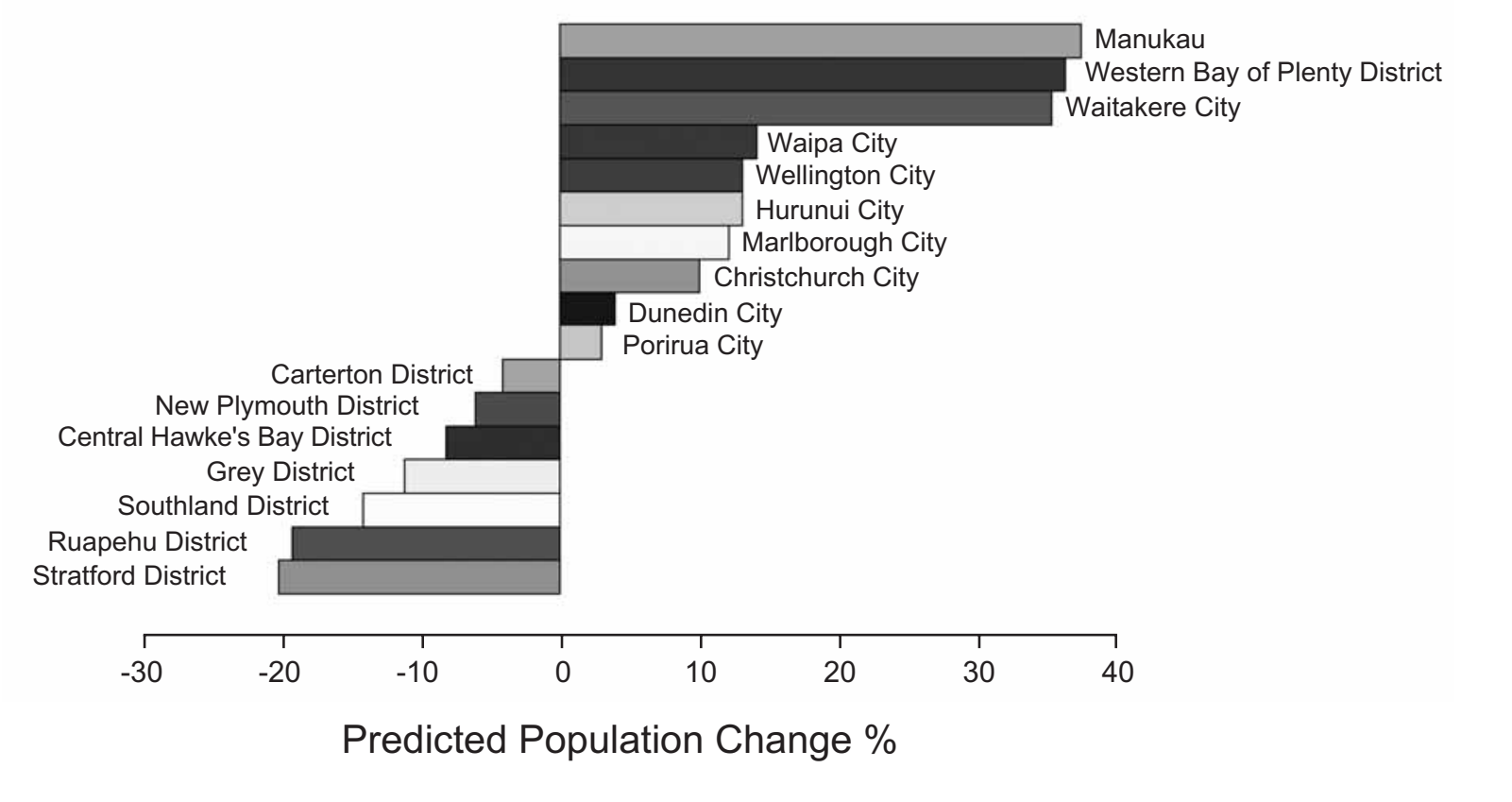


Tauranga. Hamilton is predicted to experience a $26 \%$ growth in population and Tauranga a $46 \%$ increase between 2001 and 2021. In both instances significant population growth is generated outside their boundaries by inward migration. Yet the two councils have addressed this urban growth pressure in completely different ways.

\section{Waipa District Council}

The Waipa District Council believes the economy of the district will continue to depend on agriculture and its support industries, so it emphasises the need to protect the region's environment, production base and soils, controlling development to maintain a high-quality rural lifestyle. This means confining industry and residential development to specified areas.

The council has undertaken strategic planning since the early 1990s. Key issues and community wishes have been established and incorporated into district plans. With the passage of the LGA 2002, however, the council decided to undertake a full consultation exercise in preparation for the 2004-14 LTCCP. A questionnaire sought the views of all households and businesses and some 400 community groups and stakeholders. The council endeavoured to play the role of facilitator, providing a blank canvas rather than offering its own views.

From the 400 responses, 22 outcomes were distilled and grouped under five high-level goals: 'sustainable Waipa', 'healthy community', 'economic security', 'liveable Waipa' and 'vibrant and strong community'. In the LTCCP document the council does not specify the roles of other entities such as central government and regional government, though the plan notes partnerships with others which are important to achieving the outcomes.

The LTCCP sets out in matrix form the linkages between the council's seven 'significant activities' and its highlevel goals. Each significant activity contributes to more than one goal: environmental services, for example, contributes to them all. The LTCCP reviews each of the significant activity programmes for the 2003/0420013/14 period, including any major initiatives planned, performance measures and a 10-year budget. All the district council's activities are included in the LTCCP, which has become its key planning and financial control statement. Inflation and growth forecasts are built into the projections, so any variations from the LTCCP must be specified and justified.
While much of the LTCCP covers the provision of services and the regular upgrading of infrastructure, overriding strategic issues are how to manage growth in the district to reflect the residents' wishes and how to limit rate increases. This entails limiting land fragmentation by zoning, channelling industry into dedicated areas, and limiting the number of lifestyle blocks and confining them to clusters, thus avoiding the need to provide major infrastructure to support fragmented growth. The council also wants to channel new development so that community centres are preserved, for example by putting new retail facilities in town centres rather than on their outskirts.

\section{Western Bay of Plenty District Council}

The Western Bay of Plenty District Council has generally welcomed growth, and addressed the related issues on a sub-regional scale in partnership with the Tauranga City Council and Environment Bay of Plenty. A jointly-produced SmartGrowth plan, approved in 2004, governs land use and the efficient provision of infrastructure and services.

SmartGrowth calls for urban and industrial development to be located in specified areas. Infrastructure, environmental protection and lifestylerelated measures follow from SmartGrowth land-use decisions. They lead into planning for the provision of regional transportation corridors, local roads, water supply, and waste water treatment and disposal. While SmartGrowth was formally approved after the LTCCP was finalised, many of the supporting programmes are anticipated in the LTCCP.

Since the LTCCP was published the council has also worked with Tauranga City and the regional council to develop a SmartEconomy strategy, a parallel document to SmartGrowth. It concludes that a more skilled workforce and more investment in employment opportunities are needed. It also calls for more recreational and cultural opportunities, and initiatives to achieve these ends are being developed.

In response to the outcomes specified as desirable by the community, the Western Bay of Plenty District Council set out a plan of action in the LTCCP under four strategic headings:

- Leadership 
- Building communities

- Protecting the environment

- Supporting the economy.

Leadership is treated as an overarching activity governing the other three.

Strategy is one thing, funding another. Central government has shown some interest but is yet to make any financial commitment. Environment Bay of Plenty (which has a major holding in the Port of Tauranga) is clearly viewed as a source of significant funding, as are two other councils in the district.

While all the council's activities are included in the LTCCP, a few go to the heart of the big strategic issue of rapid growth in the region: sustainable development, transportation, Tauranga and the port, water supply and waste management. Lack of funding by central government is among the risks of the strategy, since the district council cannot provide needed infrastructure, including such major items as a second harbour bridge, from its existing revenue base.

\section{Similarities and differences}

The two councils have chosen quite different approaches to their strategic planning, which they had both initiated well in advance of the LGA 2002. Waipa chose to undertake its planning alone, independently of its large neighbour, and sought to maintain its existing character, envisioning the future as a better version of the present. Western Bay of Plenty recognises that its future will inevitably be dominated by Tauranga, and so has taken a cooperative approach, seeking involvement in shaping the forces that will determine its future. It planning document is outward-looking, because central government funding is critical to realising the strategy.

While Waipa also recognises that growth is its main strategic issue, it seeks to slow it to a pace that is manageable and acceptable to the community. While the Waipa council participates in various regional forums, it has not apparently joined regional efforts to address growth issues. Waipa is more conservative and cautious; its preference is to maintain the status quo as far as possible, reflecting the community's wishes.

Both councils appear to have adequate strategic planning and decision-making mechanisms. Clearly, Western Bay of Plenty is the more progressive in approach, and the more comprehensive in its community consultation and strategic planning. It probably also has a greater planning capability - but then it needs it. Key questions are whether Waipa's approach to development is sustainable in the longer term, and whether Western Bay of Plenty will regret so readily accepting the apparently inevitable.

\section{The central government-local government interface}

The relationship between central government and local government has been strengthened over recent years. However, large questions remain about the potential for whole-of-government strategy to develop, given difficulties in aligning central and local government strategies and priorities, and the fact that central government itself lacks much of a framework to guide or participate in the development of LTCCPs.

Strategy at the central government level is often sectoral rather than overarching, and alters with a change in government. Local authorities need to collaborate with many separate agencies, and central government's interest and willingness to engage with local authorities is not mandated. The complexity of the relationship has been increased by applying the same outcome-based planning approach to both territorial and regional councils, and there are some tensions between the strategic implications of the LGA 2002 and the Resource Management Act.

The government has responded to these issues by introducing measures to improve communication and reduce duplication. Four ministries have been asked to provide a lead, each in relation to one of the four categories of well-being specified in the LGA 2002:

- Economic well-being: Ministry for Economic Development (MED)

- Cultural well-being: Ministry for Culture and Heritage $(\mathrm{MCH})$

- Social well-being: Ministry for Social Development (MSD)

- Environmental well-being: Ministry for the Environment (MfE).

The ability and propensity of the ministries to actively engage with councils varies greatly. MSD has a regional capacity, and actively engages with territorial local authorities. $\mathrm{MCH}$, a small ministry, has had to rely on 
an engagement strategy run from its national office. MED appears to have a determined preference to engage only at a regional level.

The Department of Internal Affairs has a mandate to coordinate the government's interface efforts and has a small team of regional staff facilitating engagement. Within the bureaucracy there is also a Central Government Department Group which provides a forum to discuss central/local government engagement issues, a grouping of the four 'outcome' ministries, with Internal Affairs again looking at engagement issues, and a Deputy Secretaries Group that coordinates overall engagement, including the government's urban affairs and sustainable cities initiatives. The recent establishment of an Auckland office by several ministries has the goal of fostering greater alignment of priorities and efforts by central government towards the sustainable economic and urban development of the Auckland region.

Achieving a whole-of-government approach is also limited by the diversity and capacity of local authorities, which is perhaps also responsible for the failure of central government to undertake a systematic programme of devolution. The limited articulation of national wholeof-government strategies linked to economic, social, environmental and cultural outcomes also makes it difficult to contribute to these outcomes at local and regional levels. However, the government appears to be establishing a growing number of national policy statements and service standards. These may paradoxically limit the ability of communities to pursue different or contradictory outcomes in efforts to cater for diversity in communities, or at least recognise the value of doing so.

\section{Auditing the future}

For the first time - possibly anywhere in the world each draft LTCCP must be audited before being released for public consultation, and again after the consultation process is complete and the final plan adopted. The draft audit focuses on the quality of information behind each council's 10-year financial and activity forecast, and the assumptions underlying the information. Councils have found the audit of the draft plan a major logistical challenge and smaller councils have expressed considerable disquiet about the cost - for some it represents a more than $1 \%$ rates increase.
The audit has required councils to look more closely at the quality of their long-term plans and financial projections, and particularly the quality of the asset management plans. It is clear that relationships between some councils and auditors are strained because of different expectations about reasonable compliance in terms of both the processes and content of a council's LTCCP. At the time of writing 77 of the 85 councils' draft plans had been audited, and only two have received seriously qualified audits. The danger is that planners will write plans for the auditors rather than plans for communities.

Perhaps not surprisingly, the larger councils tended to have specialist staff working on the process, had more engagement with stakeholders, and tried more innovative approaches for consulting and engaging with communities. The larger councils also had a longer history of collaborative planning. The Office of the Attorney General has agreed to examine the LTCCP process once it is complete, to evaluate its approach and decide whether amendments are needed before the next LTCCP, which will be adopted by most councils in July 2009.

\section{Conclusion}

Whether the articulation of community outcomes and strategic plans adds value to communities will depend on whether they foster cooperation and collaboration among units of local government and central government, thereby achieving the synergies needed for whole-of-government approaches to policy development and service delivery.

When central government mandates strategic planning for local governments there is a risk that concerns about compliance and passing muster with the auditor can thwart creative strategic thinking. Under current arrangements, collaboration and engagement by central government departments is voluntary rather than required. Some local authorities believe that similar longterm planning frameworks should be mandated at central government level.

There is optimism and pessimism about the longterm impacts of the legislated changes. If successful, the mandated strategic planning process will enable communities to become more innovative and capable of thinking and acting strategically. The value added from community strategic planning depends on an 
ability to draw effective linkages between community outcomes, council outputs, and strategies of other key organisations which influence outcomes. In this respect the way in which local government strategic planning does or does not link to central government strategy is crucial.

\section{References}

Bryson, J. (2004) Strategic Planning for Public and Nonprofit Organizations: a guide to strengthening and sustaining organizational achievement, San Francisco: Jossey-Bass.

Goldsmith, S. and W. Eggers (2004) Governing by Network: the new shape of the public sector, Washington: The Brookings Institution.

Huxham, C. (2003) 'Theorizing collaborative practice', Public Management Review, 5 (3), pp:401-23.

Lawrence, E. (1999) 'Strategic Thinking: a discussion paper', Research Directorate, Public Service Commission of Canada.

Local Futures Research Project (2004), 'Local Government's Role in Strategic Policy and Planning', working paper, October, www.localfutures.ac.nz.

Local Futures Research Project (2005) 'Local Government and Community Outcomes under the LGA 2002 Act', working paper, December, www.localfutures.ac.nz.

Local Futures Research Project (2006) Local Government, Strategy and Communities, Wellington: Institute of Policy Studies, 2006.

McKinlay, P. (2004) Realising the Potential of the Community Outcomes Process, Wellington: Local Government New Zealand, http://library.lgnz.co.nz/cgibin/koha/opac-detail.pl?bib=3337.

Mintzberg, H., B. Ahlstrand, and J. Lampel (1998) Strategy Safari: a guided tour through the wilds of strategic management, New York: The Free Press.

Office of the Auditor General (2005) Auditing the Future: self assessment process and group descriptors, Wellington: Office of the Auditor General, www.oag.govt.nz.
Mike Reid is Strategy Manager, Local Government New Zealand; Claudia Scott is Professor of Public Policy, School of Government, Victoria University of Wellington; and Jeff McNeill is a public policy consultant. All three are researchers with the Local Futures Project and acknowledge contributions from other project members, in particular, Chris Yandle, a Local Futures research associate, who completed research on the Waipa and Bay of Plenty District Councils. 